\title{
Clinical Observation of Ginger Partitioned Moxibustion Combined with Acupuncture in the Treatment of Breast Fibroma
}

\author{
XIU JUAN LI, WEI JIAO ZHANG ${ }^{1}$, DONG WEI SUN², MO LI ZHANG, SHI QI AI, XIN YAN JIA, XIAO CHENG NI AND CHUN \\ HONG ZHANG*
}

Department of Acupunctue, 'Department of Chinese internal Medicine, Shenzhen Baoao Authentic TCM Therapy Hospital, No. 99, Lai'an Road, 'Department of Rehabilitation, The Fifth Affiliated Hospital of Shenzhen University, No. 60 Leyuan Street, Xixiang Street, Shenzhen, Guangdong 518126, China

Li et al.: Clinical Observation of Ginger Partitioned Moxibustion in Treatment of Breast Fibroma

To investigate the clinical efficacy of ginger partitioned moxibustion combined with acupuncture in the treatment of breast fibroma. 128 cases of breast hyperplasia combined with breast fibroma in our hospital from June 2018 to June 2020 were selected as the research object, and they were randomly divided into the observation group and the control group, 64 cases in each group. The patients in the control group were given Rupixiao, 5 tablets each time, 3 times a day, while the patients in the observation group were treated with ginger partitioned moxibustion combined with acupuncture for 3 mo. The levels of sex hormones (luteinizing hormone, estradiol, prolactin and progesterone), the pathological characteristics of color Doppler ultrasound and the changes of quality of life of the two groups before and after treatment were observed and analyzed, and the therapeutic effect was evaluated. After treatment, the estradiol and prolactin levels of the two groups were lower than before treatment, Progesterone and luteinizing hormone levels were higher than before treatment, and the estradiol and prolactin levels of the observation group were lower than those of the control group, progesterone and luteinizing hormone levels were higher than those of the control group, the differences were statistically significant $(\mathbf{p}<\mathbf{0 . 0 5})$; After treatment, the thickness of mammary gland layer, the diameter of mass, the inner diameter of breast duct and the diameter of hypoechoic area of the two groups were lower than before treatment, and the observation group was lower than the control group, the difference was statistically significant $(p<0.05)$; After treatment, the quality of life Generic Quality of Life Inventory-74 scores (including material life, physical function, social function, psychological function and total score) of the two groups were significantly improved $(p<0.05)$, and the observation group was significantly better than the control group in improving the quality of life scores; The total effective rates of the observation group and the control group were $95.0 \%$ and 83.3 $\%$ respectively, and the difference between the two groups was statistically significant $(p<0.05)$. Ginger partitioned moxibustion combined with acupuncture in the treatment of patients with breast fibroma has a good effect, which can effectively improve the level of sex hormones, promote the recovery of the disease, and improve the quality of life of patients.

Key words: Breast fibroma, ginger partitioned moxibustion, acupuncture, sex hormone level

Breast fibroma is a disease that acts on ductal epithelial cells and fibrous connective tissue. Hyperplasia and degenerative changes of breast tissue can lead to hyperplasia of breast, which is related to the disorder of sex hormone metabolism ${ }^{[1,2]}$. As a common complication of breast hyperplasia, patients with breast fibroma lose the balance of hormone regulation, estrogen levels continue to rise, breast epithelial tissue and fibrous tissue hyperplasia, leading to the formation of breast fibroma $^{[3]}$. Breast hyperplasia with breast fibroma is characterized by breast mass, often accompanied by mild breast pain. In western medicine, surgical resection is commonly used, but its endocrine imbalance cannot be improved, so it is easy to relapse and leave scars on the breast, which cannot be accepted by the majority of women. The use of traditional Chinese medicine

*Address for correspondence

E-mail: rrrwefrew@163.com 
acupuncture and ginger partitioned moxibustion in the treatment of hyperplasia of mammary glands can not only treat both inside and outside, but also leave no scars, which is easy to be accepted by the majority of patients ${ }^{[4-6]}$. In this study, acupuncture combined with ginger partitioned moxibustion in the treatment of breast fibroma can not only regulate the endocrine as a whole, but also solve the local problems, so as to further clarify the exact curative effect of acupuncture combined with ginger partitioned moxibustion in the treatment of breast fibroma, and provide an effective treatment plan and reliable theoretical basis for clinical practice. A total of 128 cases of breast hyperplasia combined with breast fibroma in our hospital from June 2018 to June 2020 were selected as the research objects and randomly divided into observation group and control group, 64 cases in each group. The patients in the observation group were $21-45 \mathrm{y}$ old, with an average of (32.65 \pm 3.40$) \mathrm{y}$; the course of disease was 1-7 y, with an average of $(3.60 \pm 0.75) \mathrm{y}$; the diameter of the mass was $0.9-3.9 \mathrm{~cm}$, with an average of $(1.36 \pm 0.27) \mathrm{cm}$; 48 cases of single mass, 18 cases of multiple mass; 46 cases of unilateral breast disease, 18 cases of bilateral breast disease. In the control group, the average age was disease was $(4.01 \pm 0.83)$ y (range, $1-8 \mathrm{y}$ ); the average diameter of the mass was $(1.39 \pm 0.42) \mathrm{cm}$ (range, 0.8 $3.9 \mathrm{~cm}$ ); 49 cases of single mass, 19 cases of multiple mass; 47 cases of unilateral breast disease, 18 cases of bilateral breast disease. There was no significant difference in general information between the two groups $(p>0.05)$. All patients agreed to participate in the trial and signed the informed consent. Inclusive criteria: Patients with breast fibroma diagnosed by MRI and other imaging examinations ${ }^{[7]}$; Patients with breast hyperplasia diagnosed by X-ray and pathology ${ }^{[8]}$; Patients aged 18-65 y. Exclusion criteria: Patients with severe heart, liver, kidney and other important organ diseases; Patients with tumor diameter $>5 \mathrm{~cm}$; Patients with breast malignant tumor; Patients with mental diseases who cannot cooperate with treatment. The patients in the control group were given Rupixiao tablets, 5 tablets each time, 3 times a day, 30 min after meals with warm water, $15 \mathrm{~d}$ before taking, taking until menstruation, continuous treatment for 3 mo. During the treatment, the patients were advised not to eat greasy, cold food and keep a cheerful and optimistic mood. The observation group was treated with ginger partitioned moxibustion combined with acupuncture. Selected points: Tanzhong, Rugen, Wuyi, Qimen, Fenglong, Jianjing, Neiguan, Zusanli, Taichong and (32.21 \pm 3.68$)$ y (range, $22-47 \mathrm{y}$ ); the average course of

Sanyinjiao. The specific operation is as follows:

Acupuncture: the subjects took the sitting position, wiped and disinfected the acupuncture part with $75 \%$ alcohol cotton ball and used and I brand $0.25 \times 40 \mathrm{~mm}$ stainless steel filiform needle with good elasticity. The needling direction of Rugen point is oblique needling to nipple about $20 \mathrm{~mm}$, that of Tanzhong point is horizontal needling down about $30 \mathrm{~mm}$, that of Ganshu point is oblique needling to inner side about $30 \mathrm{~mm}$, that of Jianjing is oblique needling about $30 \mathrm{~mm}$, that of Zusanli is straight needling about $30-35 \mathrm{~mm}$ The method was flat reinforcing and flat reducing, and the filiform needle was pulled out 30 min later. Ginger partitioned moxibustion: adopt constant temperature moxibustion apparatus. The patient was in supine position, and moxibustion was applied at the breast mass, the breast root and the middle part. Cut ginger into slices of 3-4 $\mathrm{cm}$ long, $2-3 \mathrm{~cm}$ wide and $0.2-0.3 \mathrm{~cm}$ thick, pierce with thick needle in the middle, put the prepared ginger slices on the moxibustion site, light the thunder fire moxibustion strip, put it into the constant temperature moxibustion set, cover it, then put the constant temperature moxibustion set on the moxibustion site and wrap it with large bath towel, fix it, the temperature is based on the patient's feeling warm, comfortable and no scald ${ }^{[7]}$. Once a day, $30 \mathrm{~min}$ a time, continuous 4 $\mathrm{d}$, rest for $1 \mathrm{~d}$, continuous treatment for $3 \mathrm{mo}$. Before treatment and one day before the end of treatment, $4 \mathrm{ml}$ of fasting venous blood was collected from the patients in the two groups. The levels of luteinizing hormone $(\mathrm{LH})$, estradiol $\left(\mathrm{E}_{2}\right)$, PRL and progesterone $(\mathrm{P})$ were detected by automatic biochemical analyzer (Shenzhen Mindray Biomedical Electronics Co., Ltd., model: bs-200). Color Doppler ultrasound (General Electric Company, model: voluson 730) was used to evaluate the breast condition of the two groups, including the thickness of the breast gland layer, the diameter of the mass, the diameter of the breast duct and the diameter of the hypoechoic area.

Curative effect evaluation refers to "expert consensus on diagnosis and treatment of breast hyperplasia", cure: breast pain or breast mass disappeared, and no recurrence $>3$ months. Marked effect: the maximum diameter of the mass was reduced by more than $1 / 2$ and the pain disappeared. Effective the maximum diameter of the mass is less than $1 / 2$, but the pain is relieved; or the maximum diameter of the mass is more than $1 / 2$, but the pain is not relieved obviously. Invalid: the mass did not shrink, even enlarged or hardened; or only the breast pain was relieved, but the mass did not shrink. Quality of life score referring to the general quality of 
life inventory-74 (GQOLI-74), the questionnaire includes four dimensions of material life, physical function, social function and psychological function and 20 factors. The higher the score, the better the quality of life. SPSS 22.0 software was used to analyze the data. Measurement data were expressed as mean \pm standard deviation $(\mathrm{x} \pm \mathrm{s})$, paired $\mathrm{t}$-test was used for intra group comparison and independent sample t-test was used for inter group comparison; counting data were expressed as percentage or constituent ratio, and chi square test was used for inter group comparison. $\mathrm{p}<0.05$ means the difference is statistically significant. After treatment, the $\mathrm{E}_{2}$ and PRL levels of the two groups were significantly lower than those before treatment and the $\mathrm{P}$ and LH levels were significantly higher than those before treatment. The $\mathrm{E}_{2}$ and PRL levels of the observation group were lower than those of the control group, and the $\mathrm{P}$ and LH levels were significantly higher than those of the control group (all $\mathrm{p}<0.05$ ), as shown in Table 1. After treatment, the thickness of mammary gland layer, the diameter of mass, the inner diameter of breast duct and the diameter of hypoechoic area of the two groups were lower than before treatment, and the observation group was lower than the control group (all $\mathrm{p}<0.05$ ), as shown in Table 2. As shown in Table 3, the total effective rates of the observation group and the control group were $96.87 \%$ and $89.06 \%$ respectively, and the difference between the two groups was statistically significant $(\mathrm{p}<0.05)$. As shown in Table 4, before treatment, there was no significant difference in GQOLI-74 scores (including material life, physical function, social function, psychological function and total score) between the two groups ( $\mathrm{p}>0.05)$. After treatment, the GQOLI-74 scores of the two groups were significantly improved $(\mathrm{p}<0.01)$, and the observation group was significantly better than the control group in improving the quality of life scores, the differences were statistically significant $(\mathrm{p}<0.01)$. The etiology and mechanism of breast fibroma are not clear, and some studies believe that hormone level disorder is one of the causes of breast fibroma ${ }^{[9]}$. In recent years, the incidence rate of breast fibroma has been increasing. Therefore, the treatment method has attracted more and more attention. Although surgical resection can better cure the disease, the psychological endurance of female patients is relatively weak, breast has special significance for women, and it has a negative impact on the mental health of patients after operation, which reduces their quality of life ${ }^{[10]}$. Therefore, a relatively conservative and effective treatment is needed. Acupuncture treatment is the most basic and commonly used treatment method in traditional Chinese Special Issue 3, 2021 medicine ${ }^{[11]}$. Acupuncture is used as a tool to stimulate specific acupoints, dredge meridians and regulate viscera, so as to play the role of strengthening the body and removing pathogenic factors and treating diseases. Rugen point and Tanzhong point are the near selected points, which can dredge the meridians around the breast, activate blood circulation and remove blood stasis. The root of Rugen point is the fundamental meaning of the development of the breast, and it belongs to the stomach meridian of Foot Yangming with Zusanli. As a combined point of the stomach meridian, Zusanli point can fill the Qi and blood of the stomach meridian. Precisely because the stomach meridian is from the lack of basin to the lower part of the breast, the Qi of the stomach meridian can be deepened, so it can achieve the goal Dredge the role of blood circulation around the breast to treat breast fibroma. Yangming Meridian is the meridian with much blood and Qi. Hegu Point belongs to the large intestine meridian of hand Yangming. This point is the original point of large intestine meridian, which has a great effect on regulating the Qi mechanism of human body. It can regulate the Qi mechanism of human body to regulate qi, activate blood circulation and activate channels and collaterals. Therefore, it has a significant effect on the treatment of hyperplasia of mammary glands (liver stagnation and qi stagnation type). Jianjing belongs to the gallbladder meridian, and the gallbladder meridian belongs to the liver. The liver is the main reservoir of blood. Its main physiological function is to regulate blood volume and store blood. Blood is closely and inseparable with women's gynecology. Jianjing is also the meeting of Shaoyang and Yangwei. Acupuncture at this point can regulate Qi and blood, so it can mobilize the blood gas of the liver meridian, nourish the breast, and play a role in the treatment of gynecological breast diseases. The position of Tianzong point corresponds to the position of the breast, both of which belong to the Qi street in the chest. According to the records of "Lingshu Weiqi", we can acupuncture Tianzong point according to the principle of Qi street, which can make the Qi street in the chest smooth, so as to make the local meridian of breast smooth, and achieve the purpose of treating this disease. Hyperplasia of mammary glands (stagnation of liver Qi type) is mostly caused by the stagnation of liver Qi near the breast, qi stagnation and blood stasis, which makes the Qi and blood of the breast unable to run. Ganshu point is the point where the Qi and blood channels of the liver converge to the bladder channel, which has the function of relieving the stagnation of Qi in the liver channel. Ganshu point is the reason for selecting Ganshu point to treat breast fibroma. Acupuncture at Indian Journal of Pharmaceutical Sciences 
the above acupoints can make the Qi and blood of local breast stasis run smoothly, and regulate the whole blood Qi of the body, so that it can get normal circulation, achieve the special effect of relieving depression and soothing liver, promoting qi and relieving pain, so as to play a role in the treatment of breast fibroma. Studies have shown that moxibustion has the function of improving immunity, and moxibustion has the function of regulating and promoting endocrine, reproduction, digestion, absorption and other system functions, and improving the function of circulatory system $^{[12-16]}$. Ginger partitioned moxibustion used in this study is a kind of object partitioned moxibustion, which mainly through the combination of drugs and treatment methods to improve the therapeutic effect. Ginger partitioned moxibustion has the functions of warming meridians and dredging collaterals, removing toxin and removing pathogenic factors and tonifying yang qi. Ginger has the function of relieving exterior, dispersing cold, dredging collaterals and degrading. The combination of ginger and moxibustion can gather concentrated medicine area in the body breast lesion site, around the breast lesion site and acupoints. Under the effect of heat, it can penetrate into the deep layer of breast tissue, so as to regulate the blood circulation around the breast. The hyperplasia of mammary glands is caused by the obstruction of Qi and blood in mammary meridians and the inability of mammary fibrous tissue to develop through the normal path. Ginger partitioned moxibustion can stimulate the biological molecules in the body, supply the necessary resources for human cells through the nerve body fluid circulation, and play the functions of dispelling wind and dispersing cold, warming meridians and collaterals, strengthening the body and removing pathogenic factors, promoting blood circulation and removing blood stasis and removing nodules. Acupuncture combined with ginger partitioned moxibustion is an internal and external treatment for breast fibroma. Internal treatment of acupuncture can regulate the Qi of channels and collaterals locally and as a whole, dredge the Qi and blood stagnated near the breast, and makes the Qi and blood of the whole body and the breast run. Ginger partitioned moxibustion external treatment; the heat generated by the burning of drugs enters into the body through the skin, which plays the role of promoting blood circulation and warming meridians. The combination of the two can play the role of soothing the liver and regulating qi, removing blood stasis and relieving pain, so as to achieve the purpose of treating breast fibroma. The results showed that after treatment, the levels of $\mathrm{E}_{2}$ and PRL in the two groups were lower than before treatment, and the levels of P and LH in the observation group were higher than before treatment $\mathrm{E}_{2}, \mathrm{PRL}$ levels were lower than the control group, $\mathrm{P}$ and LH levels were higher than the control group, two groups of patients with breast gland layer thickness, tumor diameter, breast duct diameter and hypoechoic area diameter were lower than before treatment, and the observation group was lower than the control group, the recurrence rate of the observation group was lower than the control group. These results show that acupuncture treatment of patients with hyperplasia of mammary glands of liver stagnation type can effectively improve the sex hormone level and the condition of the disease, which is conducive to improving the prognosis. At the same time, the quality of life and treatment effect of the observation group were significantly improved after treatment, which was significantly better than that of the control group. Therefore, acupuncture combined with ginger partitioned moxibustion is an ideal treatment for breast fibroma. In conclusion, ginger partitioned moxibustion combined with acupuncture in the treatment of patients with breast fibroma has a good effect, which can effectively improve the level of sex hormones, promote the recovery of the disease, and improve the quality of life of patients, so it is worthy of clinical application.

TABLE 1: COMPARISON OF SEX HORMONE LEVELS BETWEEN THE TWO GROUPS BEFORE AND AFTER TREATMENT

\begin{tabular}{|c|c|c|c|c|c|c|c|c|c|}
\hline \multirow{2}{*}{ Group } & \multirow{2}{*}{$\mathbf{N}$} & \multicolumn{2}{|c|}{$\mathrm{E}_{2}(\mathrm{pg} / \mathrm{ml})$} & \multicolumn{2}{|c|}{ PRL (ng/ml) } & \multicolumn{2}{|c|}{$P(\mathrm{ng} / \mathrm{ml})$} & \multicolumn{2}{|c|}{$\begin{array}{c}\text { LH (mlU/ } \\
\text { ml) }\end{array}$} \\
\hline & & $\begin{array}{c}\text { Before } \\
\text { treatment }\end{array}$ & $\begin{array}{c}\text { After } \\
\text { treatment }\end{array}$ & $\begin{array}{c}\text { Before } \\
\text { treatment }\end{array}$ & $\begin{array}{c}\text { After } \\
\text { treatment }\end{array}$ & $\begin{array}{c}\text { Before } \\
\text { treatment }\end{array}$ & $\begin{array}{c}\text { After } \\
\text { treatment }\end{array}$ & $\begin{array}{l}\text { Before } \\
\text { treatment }\end{array}$ & $\begin{array}{c}\text { After } \\
\text { treatment }\end{array}$ \\
\hline $\begin{array}{l}\text { Observation } \\
\text { group }\end{array}$ & 64 & $163.62 \pm 22.48$ & $123.79 \pm 12.09^{*} \#$ & $29.27 \pm 2.10$ & $21.06 \pm 2.19^{*} \#$ & $10.23 \pm 2.51$ & $14.67 \pm 2.08^{*} \#$ & $6.29 \pm 1.24$ & $17.38 \pm 2.11^{*} \#$ \\
\hline $\begin{array}{l}\text { Control } \\
\text { group }\end{array}$ & 64 & $163.58 \pm 22.47$ & $141.59 \pm 13.15^{*}$ & $29.24 \pm 2.09$ & $24.83 \pm 2.01^{*}$ & $10.18 \pm 2.52$ & $12.56 \pm 1.13^{*}$ & $6.26 \pm 1.23$ & $14.19 \pm 1.67^{*}$ \\
\hline
\end{tabular}

Note: compared with before treatment, ${ }^{*}$ is $\mathrm{p}<0.05$; compared with control group, $\#$ is $p<0.05$. 
www.ijpsonline.com

TABLE 2: COMPARISON OF BREAST COLOR DOPPLER ULTRASOUND CHANGES BETWEEN THE TWO GROUPS

\begin{tabular}{|c|c|c|c|c|c|c|c|c|c|}
\hline \multirow{2}{*}{ Group } & \multirow{2}{*}{$\mathbf{N}$} & \multicolumn{2}{|c|}{$\begin{array}{c}\text { Thickness of mammary } \\
\text { gland layer }\end{array}$} & \multicolumn{2}{|c|}{ Diameter of mass } & \multicolumn{2}{|c|}{$\begin{array}{c}\text { Inner diameter of milk } \\
\text { delivery tube }\end{array}$} & \multicolumn{2}{|c|}{$\begin{array}{c}\text { Diameter of hypoechoic } \\
\text { area }\end{array}$} \\
\hline & & $\begin{array}{c}\text { Before } \\
\text { treatment }\end{array}$ & $\begin{array}{c}\text { After } \\
\text { treatment }\end{array}$ & $\begin{array}{c}\text { Before } \\
\text { treatment }\end{array}$ & $\begin{array}{c}\text { After } \\
\text { treatment }\end{array}$ & $\begin{array}{c}\text { Before } \\
\text { treatment }\end{array}$ & $\begin{array}{c}\text { After } \\
\text { treatment }\end{array}$ & $\begin{array}{c}\text { Before } \\
\text { treatment }\end{array}$ & $\begin{array}{c}\text { After } \\
\text { treatment }\end{array}$ \\
\hline $\begin{array}{l}\text { Observation } \\
\text { group }\end{array}$ & 64 & $14.24 \pm 1.41$ & $6.11 \pm 0.73^{*} \#$ & $3.42 \pm 0.54$ & $2.14 \pm 0.42^{*} \#$ & $2.31 \pm 0.51$ & $1.79 \pm 0.41 * \#$ & $24.63 \pm 4.21$ & $10.68 \pm 1.77^{*} \#$ \\
\hline $\begin{array}{l}\text { Control } \\
\text { group }\end{array}$ & 64 & $14.27 \pm 142$ & $10.18 \pm 1.24^{*}$ & $3.40 \pm 0.53$ & $1.02 \pm 0.31^{*}$ & $2.30 \pm 0.49$ & $1.08 \pm 0.34^{*}$ & $24.59 \pm 4.20$ & $17.19 \pm 2.08^{*}$ \\
\hline
\end{tabular}

Note: compared with before treatment, * is $p<0.05$; compared with the control group, \# is $p<0.05$.

TABLE 3: COMPARISON OF CLINICAL EFFICACY BETWEEN THE TWO GROUPS

\begin{tabular}{lcccccc}
\hline Group & N & Cure & $\begin{array}{c}\text { Remarkable } \\
\text { effect }\end{array}$ & Effective & Ineffective & $\begin{array}{c}\text { Total effective } \\
\text { rate }\end{array}$ \\
\hline $\begin{array}{l}\text { Observation } \\
\text { group }\end{array}$ & 64 & 8 & 28 & 26 & 2 & $96.87 \% \#$ \\
Control group & 64 & 4 & 26 & 27 & 7 & $89.06 \%$ \\
\hline
\end{tabular}

Note: compared with the control group, \# is $p<0.05$.

TABLE 4: COMPARISON OF GQOLI-74 SCORES OF QUALITY OF LIFE BETWEEN THE TWO GROUPS BEFORE AND AFTER TREATMENT

\begin{tabular}{|c|c|c|c|c|c|c|c|}
\hline Group & $\mathbf{N}$ & Time & Material life & $\begin{array}{l}\text { Somatic } \\
\text { function }\end{array}$ & $\begin{array}{c}\text { Social } \\
\text { function }\end{array}$ & $\begin{array}{l}\text { Psychological } \\
\text { function }\end{array}$ & Total score \\
\hline \multirow[t]{2}{*}{$\begin{array}{l}\text { Observation } \\
\text { group }\end{array}$} & 64 & $\begin{array}{c}\text { Before } \\
\text { treatment }\end{array}$ & $40.13 \pm 1.07$ & $42.14 \pm 1.02$ & $40.45 \pm 1.12$ & $41.07 \pm 1.04$ & $161.33 \pm 2.06$ \\
\hline & 64 & $\begin{array}{c}\text { After } \\
\text { treatment }\end{array}$ & $49.72 \pm 1.16^{*}$ & $50.14 \pm 1.32$ * & $48.72 \pm 2.14^{*}$ & $48.12 \pm 1.36^{*}$ & $199.69 \pm 2.99 *$ \\
\hline \multirow[t]{2}{*}{ Control group } & 64 & $\begin{array}{l}\text { Before } \\
\text { treatment }\end{array}$ & $40.22 \pm 1.10$ & $42.18 \pm 1.06$ & $40.49 \pm 1.16$ & $41.11 \pm 1.07$ & $162.04 \pm 2.08$ \\
\hline & 64 & $\begin{array}{c}\text { After } \\
\text { treatment }\end{array}$ & $60.42 \pm 1.24^{*} \#$ & $59.80 \pm 1.68^{*} \#$ & $59.24 \pm 1.56^{*} \#$ & $58.92 \pm 1.60 * \#$ & $212.42 \pm 3.04^{*} \#$ \\
\hline
\end{tabular}

Note: compared with before treatment, ${ }^{*}$ is $p<0.05$; compared with the control group, \# is $p<0.05$.

\section{Acknowledgement:}

This work was supported by the Medical and health basic research (non-funded) project in Bao'an District, Shenzhen (No. 2020JD547), Shenzhen Baoan Traditional Chinese Medicine Development Foundation (No. 2020KJCX-KTYJ-206). XIU-JUAN LI and WEIJIAO ZHANG contributed equally to this work.

\section{Conflicts of interest:}

The authors report no conflicts of interest.

\section{REFERENCES}

1. Aapro M, Carides A, Rapoport BL, Schmoll HJ, Zhang L, Warr D. Aprepitant and fosaprepitant: a 10-year review of efficacy and safety. Oncologist 2015;20(4):450.

2. Ahmed I, Nazir R, Chaudhary MY, Kundi S. Triple assessment of breast lump. Journal of the College of Physicians and Surgeons-pakistan. J Coll Physicians Surg Pak 2007;17(9):535-8.
3. Boyd NF, Guo H, Martin LJ, Sun L, Stone J, Fishell E, et al. Mammographic density and the risk and detection of breast cancer. N Eng J Med 2007;356(3):227-36.

4. Carmichael AR. Can Vitex agnus castus be used for the treatment of mastalgia? What is the current evidence? Evid Based Complement Alternat Med 2008;5(3):247-50.

5. Early Breast Cancer Trialists Collaborative Group. Adjuvant chemotherapy in oestrogen-receptor-poor breast cancer: patient-level meta-analysis of randomised trials. Lancet 2008;371(9606):29-40.

6. Colak T, Ipek T, Kanik A, Ogetman Z, Aydin S. Efficacy of topical nonsteroidal antiinflammatory drugs in mastalgia treatment. J Am Coll Surg 2003;196(4):525-30.

7. Degnim AC, Visscher DW, Berman HK, Frost MH, Sellers TA, Vierkant RA, et al. Stratification of breast cancer risk in women with atypia: a Mayo cohort study. J Clin Oncol 2007;25(19):2671-7.

8. Detopoulou P, Panagiotakos DB, Antonopoulou S, Pitsavos C, Stefanadis C. Dietary choline and betaine intakes in relation to concentrations of inflammatory markers in healthy adults: the ATTICA study. Am J Clin Nutr 2008;87(2):424-30. 
9. Dinicola S, Chiu TT, Unfer V, Carlomagno G, Bizzarri M. The rationale of the myo-inositol and D-chiro-inositol combined treatment for polycystic ovary syndrome. J Clin Pharmacol 2014;54(10):1079-92.

10. Dona G, Sabbadin C, Fiore C, Bragadin M, Giorgino FL, Ragazzi E, et al. Inositol administration reduces oxidative stress in erythrocytes of patients with polycystic ovary syndrome. Eur J Endocrinol 2012;166(4):703.

11. Giordano D, Corrado F, Santamaria A, Quattrone S, Pintaudi B, Di Benedetto A, et al. Effects of myo-inositol supplementation in postmenopausal women with metabolic syndrome: a perspective, randomized, placebo-controlled study. Menopause 2011;18(1):102-4.

12. Go EK, Jung KJ, Kim JY, Yu BP, Chung HY. Betaine suppresses proinflammatory signaling during aging: the involvement of nuclear factor- $\kappa \mathrm{B}$ via nuclear factor-inducing kinase/I $\mathrm{KB}$ kinase and mitogen-activated protein kinases. J Gerontol A Biol Sci Med Sci 2005;60(10):1252-64.

13. Kaviani A, Mehrdad N, Najafi M, Hashemi ES, Yunesian M, Ebrahimi M, et al. Comparison of naproxen with placebo for the management of noncyclical breast pain: a randomized, double-blind, controlled trial. World J Surg 2008;32(11):2464-70.
14. Pasta V, Dinicola S, Giuliani A, Harrath AH, Alwasel SH, Tartaglia $\mathrm{F}$, et al. A randomized pilot study of inositol in association with betaine and boswellia in the management of mastalgia and benign breast lump in premenopausal women. Breast cancer 2016;10:BCBCR-S38408.

15. Pasta V, Gullo G, Giuliani A, Harrath AH, Alwasel SH, Tartaglia F, et al. An association of boswellia, betaine and myo-inositol (Eumastós $(\mathbb{R})$ in the treatment of mammographic breast density: a randomized, double-blind study. Eur Rev Med Pharmacol Sci 2015;19(22):4419-26.

16. Rapoport BL. Differential pharmacology and clinical utility of rolapitant in chemotherapy-induced nausea and vomiting. Cancer Manag Res 2017;9:41-50.

This is an open access article distributed under the terms of the Creative Commons Attribution-NonCommercial-ShareAlike 3.0 License, which allows others to remix, tweak, and build upon the work non-commercially, as long as the author is credited and the new creations are licensed under the identical terms

This article was originally published in a special issue,
"Evolutionary Strategies in Biomedical Research and
Pharmaceutical Sciences" Indian J Pharm Sci 2021:83(3)Spl
issue;77-82

